\title{
The closer the sportier? Children's sports activity and their distance to sports facilities
}

\author{
Andreas Steinmayr $\cdot$ Christina Felfe $\cdot$ Michael Lechner
}

Received: 22 February 2011 /Accepted: 28 June 2011 / Published online: 5 November 2011

(C) European Group for Research into Elderly and Physical Activity (EGREPA) 2011

\begin{abstract}
We investigate whether the distance between the next sports facilities and children's homes matter for their sports activities inside and outside of sports clubs. Our analysis is based on a large and informative crosssection of individual data on children and their families, the so-called German Health Interview and Examination Survey for Children and Adolescents data. We use a semiparametric econometric method to investigate this relationship empirically. Our results suggest that while the distance does not matter in larger towns and cities, it does matter in smaller towns and in particular on the countryside.
\end{abstract}

Keywords Sports activities of children - KiGGS data

Propensity score- matching methods

\section{Introduction}

The positive effect of physical activities on individual health is widely acknowledged both in academics and in the general public [1-4; among others]. Nevertheless, a substantial part of the population is not involved in individual sports activities. In Germany, for instance, about $31 \%$ of the population older than 15 years does not participate in sports activities at all, a share that is

\footnotetext{
A. Steinmayr $(\square) \cdot$ C. Felfe $(\square) \cdot$ M. Lechner $(\square)$

Swiss Institute for Empirical Economic Research (SEW),

University of St. Gallen,

Varnbüelstrasse 14,

CH-9000, St. Gallen, Switzerland

e-mail: Andreas.Steinmayr@unisg.ch

e-mail: Christina.Felfe@unisg.ch

e-mail: Michael.Lechner@unisg.ch

URL: www.sew.unisg.ch/lechner
}

somewhat below the European average (39\%). Another $20 \%$ participate only rarely [5]. Among German children in the age range $6-14$, the share of nonparticipants is only slightly lower, about $30 \%$ [6]. Given that sports during childhood is one of the key determinants of sports during adulthood [7], and that health during childhood is one of the key determinant of health during adulthood [8], this low number is a matter of concern.

In light of these non-activity figures, one may question the substantial public subsidies paid to the leisure sports sector in many Western countries [9]. In Germany, for instance, about $0.2 \%$ of the gross domestic product (GDP) is spent on the provision of sports-related goods and services, of which $77 \%$ are spent on the construction and maintenance of sports facilities [10]. While a positive correlation between the availability and accessibility of sports facilities and physical activity of young people has been shown by a number of studies [11-13], ${ }^{1}$ there is only scarce evidence of a causal link between the availability of sports facilities and sports engagement. Investigating the determinants of individual travel time behavior, Pawlowski et al. [19] find that sports participation is sensitive to variations in the travel time needed to reach a sports facility. Using data from a major German city (Stuttgart) and exploiting differences in the supply of sports facilities between different districts, Wicker et al. [20] find that there is a positive link between the regular sports activity and the supply of fitness centers, gymnasia, sports field, and public playgrounds in the district. However for children aged 318 years, they confirm a positive association only for swimming pools.

\footnotetext{
${ }^{1}$ So far, the literature has mainly concentrated on the association between the availability of outdoor spaces and people's physical activity [14-18].
} 
The objective of this paper is to provide more evidence on the causal impact of the local availability of sports facilities and children's sports engagement. ${ }^{2}$ The particular question we want to answer is whether children who live closer to a sports facility have a higher probability to engage in sports activities. When analyzing this question, we distinguish between sports exercised inside and outside of sports clubs. In addition, we consider different types of sports facilities, such as gyms, sports grounds, tennis courts, and indoor pools, to gain some understanding which type of sports facility is relevant to encourage children to engage in sports. We employ a semiparametric matching estimator to account for differences in the covariate distributions among children who live close to sports facilities and children who live further away from such facilities.

The remainder of the paper is structured as follows. The next section provides a brief overview of sports facilities in Germany. The "Methods" section describes the datasets we use as well as our empirical strategy. The "Results" section shows first unconditional results about the link between facilities and activity levels and then discusses the matching results. The "Conclusion" section concludes.

\section{Sports facilities in Germany}

The so-called "Golden Plan for Health and Recreation", established in the 1950s [21], constitutes the key stone for the systematic planning of sports facilities in West Germany. As its target of providing $0.2 \mathrm{~m}^{2}$ indoor and $3.25 \mathrm{~m}^{2}$ outdoor spaces for each citizen required a big extension of the existing capacity, the plan caused a major construction wave for sports facilities. As a result, the supply of sports facilities increased dramatically from around 40,000 facilities in 1960 to around 140,000 in 1988 [22]. From the 1990s onward, the supply remained rather stable at about 100,000 core sports facilities and 50,000 further sports institutions. After unification, East Germany followed the West German example and introduced the so-called "Golden Plan East", which led to an additional supply of 20,000 sports facilities in the East German states [22].

Total public expenditure for the provision of sports-related goods and services amounts to $0.2 \%$ of the German $\mathrm{GDP}^{3}$ : $77 \%$ of this amount (3.94 bio $€$ ) is used for the provision of

\footnotetext{
${ }^{2}$ Please note that throughout the paper we use the terms sports engagement, sports participation, sports activity, as well as physical activity interchangeably. Strictly speaking, the last term comprises not only guided sports activities but also nonguided activities such as hiking, cycling, or even playing.

${ }^{3}$ To put that number into perspective, note that Germany spends on average $6.2 \%$ of GDP on education, including early childcare, kindergarten, obligatory school system as well as higher education and research. Of course, some of this spending may be related to school based sports as well.
}

sports-related services and 23\% (0.9 bio $€)$ is spent on administration (e.g., management, sports events). The overall relative spending levels vary, however, dramatically across states. They range from $0.14 \%$ in North Rhine-Westphalia and Schleswig-Holstein to $0.37 \%$ in Saxony-Anhalt and even $0.41 \%$ in Thuringia. Expressed in monetary terms, this means that, on average, $49.22 €$ are spent per person for the provision of sports-related goods and services, the minimum amount spent in Hamburg (11.29 €/person) and the maximum amount spent in Baden-Wurttemberg (67.56 €/person) [10].

\section{Methods}

Data

\section{The German Health Interview and Examination Survey for Children and Adolescents}

The primary data of our analysis is the "German Health Interview and Examination Survey for Children and Adolescents" (henceforth KiGGS), which is a comprehensive, Germany-wide, representative interview and examination survey for the age group 0-17 years. The sample was selected in a two-stage process: first, 167 communities (sample points) were chosen; second, within those sample points, subjects were randomly selected from the population register. Between May 2003 and May 2006, 17,641 participants were examined and interviewed. The survey consisted of a medical examination of the children as well as a computer-assisted personal interview performed by physicians [23]. ${ }^{4}$ In addition, parents and older children (aged 11-17 years) filled in written questionnaires which provided further information on the individual background.

One feature that makes KiGGS especially suitable for our purposes is that it provides not only exhaustive information on the children's individual and family backgrounds, but also detailed information on the children's physical activities. In addition to this survey, we collected secondary data on the available sports facilities as well as local characteristics for (almost) all communities included in KiGGS. A detailed description of this database is given below. Based on the exact location of the sports facilities and the homes of the children included in KiGGS, we determine individual straight line and road distances to the closest sports facility, as well as to different types of sports facilities. Thus, the KiGGS data together with the detailed information on local conditions allow us to study the relation between children's sports participation and the availability of sports facilities in their local neighborhood.

\footnotetext{
${ }^{4}$ For more information about KiGGS, please refer to httpsozial04126://www.kiggs.de/service/english/index.html.
} 


\section{The sample}

Our interest lies not only in participation in sports activities in general, but also in those done in sports clubs in particular. Given that the latter information is only reported for children 3-10 years old, our analysis is restricted to this age range and thus to 8,023 children. Due to missing information on the individual distances to available sports facilities in the local area (550 observations) and on the individual participation in a sports club or sports outside a club (475 observations), our sample is further restricted and finally includes 6,998 children (and their families). ${ }^{5}$

\section{Measures of sports activities}

Parents were asked about the frequency with which their child was performing sports in a club and additionally about the frequency with which their child was performing sports outside of a club. They could choose between five different categories: "never", "less than once per week", "once or twice a week", "3-5 times a week", and "almost daily". Table 1 shows that with respect to participation in a sports club there are basically two groups of children, those that are not active in a sports club on a regular basis (48\%) and those who are active at least once a week (52\%). With respect to sports outside a club, the picture is similar: Half of the kids exercise at least once per week, while the other half do not exercise at all, or at least not outside a sports club - the distribution is, however, more even across all possible frequencies. Thus, in our analysis, we focus on the impact of participating in sports in a club on a regular basis $(52 \%)$ versus not participating in a sports club on a regular basis $(48 \%)$. The same distinction is made for sports exercised outside a club (50\% vs. $50 \%)$.

\section{Measures of sports facilities}

The specific sports facilities considered are gyms, sports grounds, tennis courts, and indoor pools. According to the German Olympic Association, the selected facilities should

\footnotetext{
${ }^{5}$ Note that these sample restrictions are needed because we do not possess information on sports participation nor individual distances to sports facilities for these children. Yet, to get some idea to what extent our sample is representative for all German children of age 3-10, we have performed a comparison of means for several background characteristics, such as gender, migrant status, socio-economic background, and urbanization. While missing information on the local supply of sports facilities does not lead to any statistical differences in these covariates, nonresponse to the question related to sports participation correlates with all these covariates except children's gender. Migrants, families stemming from a lower socio-economic background and families living in rather urbanized areas are less likely to respond. Thus, our results might not be representative for all German children of age 3-10.
}

Table 1 Frequency of participation in a sports club

\begin{tabular}{lccccc}
\hline & \multicolumn{2}{c}{ Sports in a club } & & \multicolumn{2}{c}{ Sports outside a club } \\
\cline { 2 - 3 } \cline { 6 - 6 } \cline { 6 - 7 } & Observations & $(\%)$ & & Observations & $(\%)$ \\
\hline Daily & 73 & $(1)$ & 672 & $(10)$ \\
3-5 Times/week & 387 & $(6)$ & 716 & $(10)$ \\
1-2 Times/week & 3,161 & $(45)$ & 2,123 & $(30)$ \\
Rarely & 429 & $(6)$ & 2,044 & $(29)$ \\
Never & 2,948 & $(42)$ & 1,443 & $(21)$ \\
\hline
\end{tabular}

serve as a location for most sports performed by children aged $0-18$ years.

Data on type and address of these facilities was collected from various sources for 163 out of the 167 communities, where families belonging to KiGGS were surveyed. ${ }^{6}$ The main sources of information were websites of municipalities, where most municipalities provide registers of available facilities. Additionally, we collected data from websites of local sports associations as well as from Google Maps. For municipalities where the relevant information could not be gathered online, we requested lists of available facilities from the municipal administration (and usually received them).

The address data from the survey participants as well as from sports facilities were geo-coded using Microsoft MapPoint Europe 2010 in combination with IC-Tools, a MapPoint AddIn for Microsoft Excel. ${ }^{7}$ Road distances between children's homes and the different sports facilities available in the community were calculated using the same software. ${ }^{8}$ Linear distances were calculated using the STATA module globdist. Finally, for each type of facility the distance to the closest facility was obtained.

Table 2 provides an overview over the mean linear distances to the closest facility of each type overall and for different subgroups. On average, the nearest gym is $1.29 \mathrm{~km}$, the nearest sports ground $1.12 \mathrm{~km}$, the nearest tennis court $2.1 \mathrm{~km}$, and the nearest indoor pool $3.87 \mathrm{~km}$ away. While the average distances are almost the same by the child's sex and age, children with an immigrant background live on average substantially closer to all types

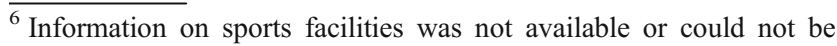
processed for four communities.

7 For addresses where MapPoint was not able to determine the exact geocode, Google Maps and Bing Maps were used instead.

${ }^{8}$ In order to keep the collection of data regarding the availability of facilities feasible, we collected only data in the communities where children were surveyed. For children who live close to the boarder of a municipality, it might therefore be the case that a specific facility in the neighboring municipality is closer than a facility of the same type in the residence municipality. In case a particular type of facility was not available in a municipality, we tried to collect the information on available facilities of this type in neighboring municipalities. However, this was not possible for all tennis courts and indoor pools. The number of observations for these two types of facilities is therefore lower than for gyms and sports grounds (see Table 2).
} 
Table 2 Mean distance $(\mathrm{km})$ to closest facilities

\begin{tabular}{|c|c|c|c|c|c|}
\hline & & \multicolumn{4}{|c|}{ Mean linear distance $(\mathrm{km})$ to closest ... } \\
\hline & & Gym & Sports ground & Tennis court ${ }^{\mathrm{a}}$ & Indoor pool ${ }^{\mathrm{a}}$ \\
\hline Total & & 1.29 & 1.12 & 2.10 & 3.87 \\
\hline \multirow[t]{2}{*}{ Age } & $3-6$ years & 1.30 & 1.13 & 2.09 & 3.95 \\
\hline & $7-10$ years & 1.27 & 1.11 & 2.11 & 3.80 \\
\hline \multirow[t]{2}{*}{ Gender } & Girl & 1.31 & 1.12 & 2.15 & 3.92 \\
\hline & Boy & 1.27 & 1.12 & 2.05 & 3.82 \\
\hline \multirow[t]{2}{*}{ Nationality } & German & 1.39 & 1.17 & 2.21 & 4.11 \\
\hline & Foreign & 0.63 & 0.79 & 1.43 & 2.45 \\
\hline \multirow[t]{3}{*}{ Social class } & Low & 1.25 & 1.13 & 2.09 & 3.75 \\
\hline & Medium & 1.41 & 1.14 & 2.29 & 4.27 \\
\hline & High & 1.12 & 1.08 & 1.80 & 3.35 \\
\hline \multirow[t]{4}{*}{ Living in a } & Village & 2.21 & 1.48 & 3.05 & 7.18 \\
\hline & Small town & 0.79 & 1.02 & 1.73 & 3.04 \\
\hline & Medium town & 0.85 & 0.99 & 1.75 & 2.45 \\
\hline & City & 0.61 & 0.76 & 1.50 & 2.09 \\
\hline \multirow[t]{2}{*}{ Part of Germany } & West & 0.99 & 0.99 & 1.76 & 3.64 \\
\hline & East & 1.92 & 1.39 & 3.29 & 4.44 \\
\hline
\end{tabular}

Note: Distance defined as straight line

${ }^{\mathrm{a}}$ Distance to tennis court is missing for 957 observations, distance to indoor pool for 793 observations sports facilities available in smaller villages/cities than in bigger cities. The positive association between the availability of sports facilities and economic conditions (higher tax income, lower unemployment and more employment in the tertiary sector), might also result from the differential availability of sports facilities across differentially big municipalities. Taken together, the difference in the supply of sports facilities across differential family background and regions highlights the need to consider these background characteristics in our analysis.

\section{Measures of background characteristics}

A summary of the individual, family background and local neighborhood characteristics can be found in Table 5 in Appendix 1. With respect to the individual characteristics of the children, children are on average 6.6 years old, where each age group is equally well represented. About half of the children are boys (51\%). Children's socio-economic background can be described as follows: The majority of the parents have a basic or intermediate school degree (among mothers 20\% and 45\%, respectively, and among fathers $25 \%$ and $34 \%$, respectively). Almost half of the sample belongs to the middle class $(46 \%)$, one quarter belongs to the lower class $(27 \%)$, and one quarter to the upper class (26\%). It is important to stress that $13 \%$ of the children are from a family with foreign background. Given that foreigners may behave differently in terms of engagement in social activities and in particular in sports activities (especially when their child is a girl), it is crucial to 


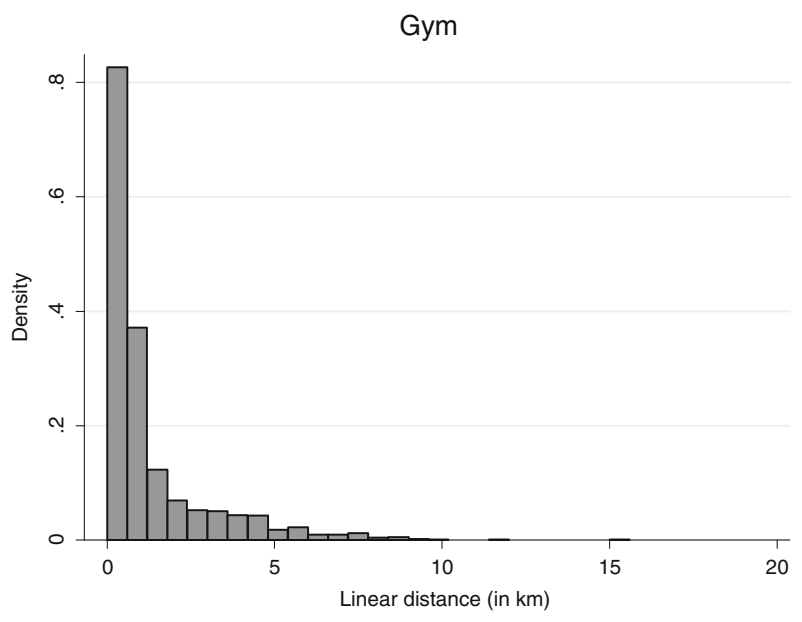

Tennis court

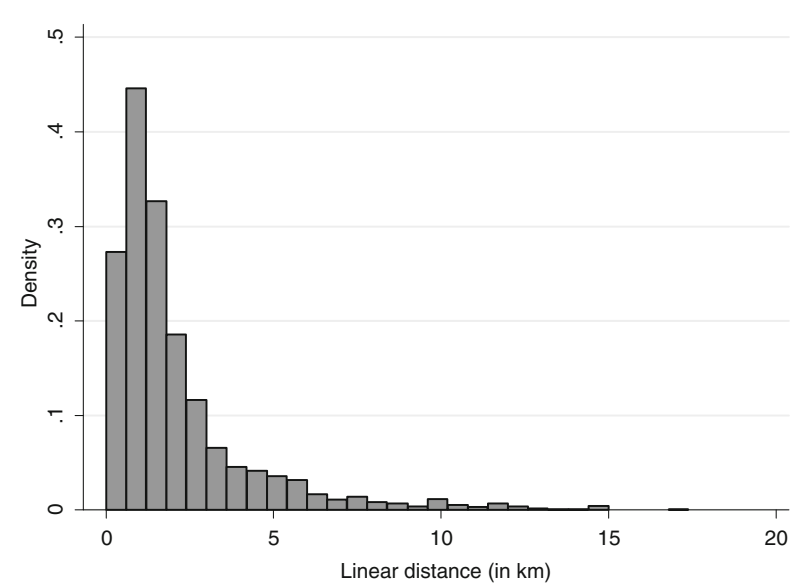

Sports ground

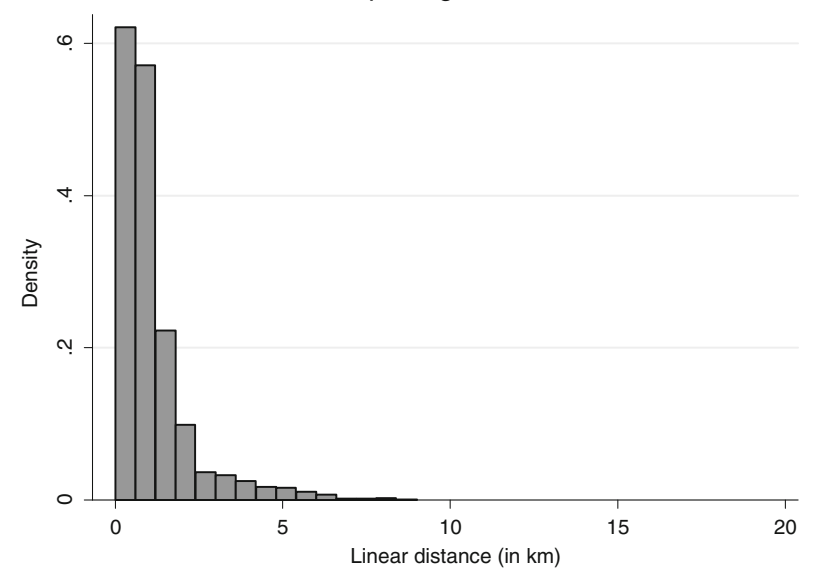

Indoor pool

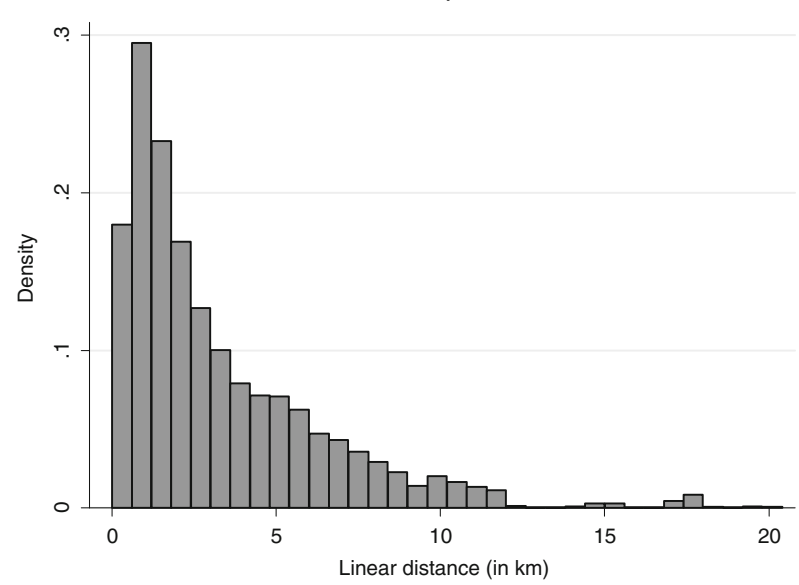

Fig. 1 Distribution of observations with respect to distance to next facility. Distance is measured as straight line

consider the cultural background in our estimation. One final noteworthy fact is that $22 \%$ of the mothers are overweight and $10 \%$ of them are even obese. Thus, physical activity seems to be highly relevant.

\section{Empirical strategy}

\section{Identification}

A simple comparison of children who are living closer to sports facilities versus children who are living further away would not provide us with reliable estimates for the causal link between the distance and the level of children's physical activity. First, the availability of sports facilities might be a result of the lobbyism of the local citizens and second, parents' location choice might be based on the amenities offered by the neighborhood. As a result, children, whose parents care more about them engaging in sports, are more likely to live in a neighborhood with abundant supply of sports facilities. Nevertheless, a potential endogeneity problem stemming from the supply of facilities is less worrying for Germany: as pointed out in "Sports facilities in Germany" section, the majority of sports facilities were constructed from 1960 to 1990 , far before our period of interest, following the so-called Golden Plan [22] - a major effort of the German government to extend and improve sports facilities. Hence, the availability of local sports facilities should be exogenous to any individual political efforts. Moreover, the data we have at hand provides us with a wide range of information about the child, her family background as well as the characteristics of her local neighborhood. This allows us to address the second concern, namely that parents' location choice might be influenced by the availability of sports facilities. We can exploit this rich source of information by employing a matching estimator, which allows us to compare children, which are similar in many individual, family, and neighborhood aspects except the local supply of sports facilities. Thus, we are confident 
Table 3 Correlation between distance to facilities and municipality characteristics

Note: All correlations are significant at the $1 \%$ significance level. Distance is measured as straight line

\begin{tabular}{lcccc}
\hline & Gym & Sports ground & Tennis court & Indoor pool \\
\hline Population density & -0.30 & -0.20 & -0.23 & -0.31 \\
Open space per inhabitant & 0.41 & 0.27 & 0.47 & 0.59 \\
Population share below 18 years & -0.13 & -0.05 & -0.11 & 0.04 \\
Tax income per capita & -0.27 & -0.17 & -0.28 & -0.27 \\
Unemployment rate & 0.10 & 0.08 & 0.13 & -0.08 \\
Labour force in tertiary sector (\%) & -0.20 & -0.06 & -0.17 & -0.18 \\
Population development & -0.17 & -0.09 & -0.24 & -0.21 \\
\hline
\end{tabular}

that the results uncover the impact of the local availability of sports-related institutions on children's physical activity.

\section{Estimation}

We estimate this effect by employing a propensity scorematching estimator. This estimation method compares the physical activity of children who live close to a sports facility (treated group) to the physical activity of children who live further away from next sports facility (control group). To avoid any selection into treatment - in other words, to eliminate any bias which may arise due to the fact that a specific type of parent wants her child to engage in sports and thus chooses to live closer to a sports facility - we adjust the two groups for differences in their covariate composition (for a discussion about the covariates, please refer to "Data" section). The adjustment is based on the propensity to live close to a sports facility, which is predicted using a probit estimation where the dependent variable is a binary indicator for having a sports facility close by (the exact list of covariates used and the estimation results are shown in Table 7 in Appendix 1). ${ }^{10}$ Note that these semiparametric matching-type estimators have the substantial advantage compared for example to standard linear or nonlinear regression types methods using parametric models that they do not require to specify the relationship between the outcome variable, the control variables and the distance. Furthermore and of course related to this, they allow the individual effects of the distance on the sports activity to be fully heterogeneous.

The remaining question in this binary setting is how to define "living close to a sports facility". ${ }^{11}$ The selection of our threshold is based on the results of the nonparametric and parametric analyses of children's propensity to engage in sports activities presented below in "Unconditional results" section. Additionally, it is clearly visible in Table 8 in Appendix 1 that the share of children being member in a

\footnotetext{
${ }^{10}$ For more details about the estimation method, please refer to Appendix 2.

${ }^{11}$ The binary setting can easily be extended to allow for the effect of various differences in distances. However, Fig. 2 strongly suggest there exist only two groups and thus, such extension would not lead to any relevant gain.
}

sports club remains stable over the first $2.5 \mathrm{~km}$ and starts decreasing thereafter. This result holds true for gyms as well as for sports grounds, both unconditional and conditional on a set of individual background variables. Given this insight, we define the binary treatment variable equal to one when living closer than $2.5 \mathrm{~km}$ to the next gym/sports ground and equal to zero when living further away than $2.5 \mathrm{~km}$. Thus, strictly speaking, we evaluate the impact of living closer than $2.5 \mathrm{~km}$ to the next facility on children's sports engagement. In particular, we estimate the following three different effects: (1) the average treatment effect (ATE), which measures the average effect on children's sports participation of having a sports facility close by; (2) the average treatment effect on the treated (ATET), which is the average effect for children who live closer than $2.5 \mathrm{~km}$ to the next sports facility; and (3) the average treatment effect for the non-treated (ATENT), which is the average effect for children who live further away than $2.5 \mathrm{~km}$ from the next sports facility.

\section{Results}

\section{Unconditional results}

The question posed in this study is whether children who live closer to sports facilities exercise more sports. In order to gain a better understanding of how children's physical activity evolves with the distance to different types of sports facilities, Fig. 2 presents nonparametric kernel estimates of children's sports participation - inside and outside of a club-in relation to the distance to four types of sports facilitiesgyms (sports halls), sports grounds, tennis courts, and indoor pools. Distance is measured as a straight line between home address and address of the sports facility. Using road distance instead does not change the findings in any substantial manner (see Fig. 4 in Appendix 1).

As we can see clearly in Fig. 2, children's participation in sports clubs decreases the further away they live from the next sports facility. This negative relation is most prominent for gyms and sports grounds. It may be explained by gyms and sports grounds serving as a location for most sports exercised by children. To be more precise, sports club 
Fig. 2 Relation of the distance to sports facilities to the level of sports participation. Nonparametric kernel regression based on the Epanechnikov kernel. A bandwidth of 0.6 is used for both figures. Distance is measured as straight line. Figure 4 in the appendix provides the same relationships using road distances
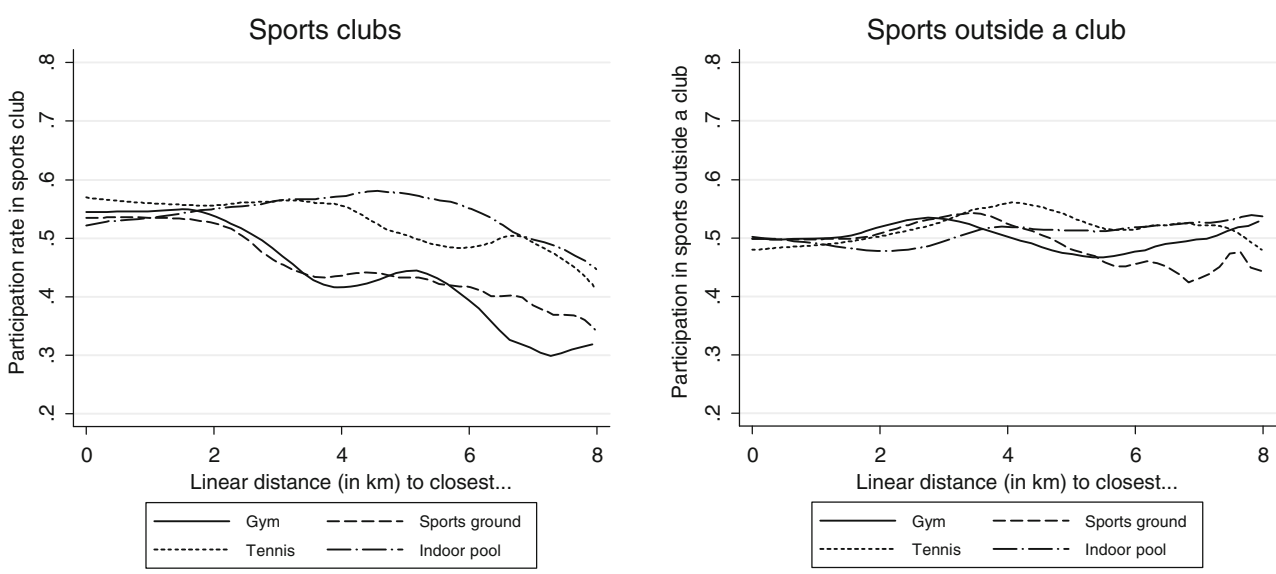

participation is rather inelastic with respect to the local supply of gyms/sports grounds over the first $2 \mathrm{~km}$. Only thereafter, we observe a strong decline in children's sports participation with an increasing distance to the closest gym/ sports ground. The negative relation is less pronounced, but still observable with respect to the distance to the closest tennis facility or indoor pool. Yet, in the case of tennis courts, children's club participation only starts decreasing when the distance exceeds $4 \mathrm{~km}$, and in the case of indoor pools only at a distance of $6 \mathrm{~km}$ and more (however, as can be seen in the histograms in Fig. 1, our measurements in these areas are based on very few observations).

Quite the contrary to sports exercised inside a club, children's physical activity outside a club seems to be inelastic to the availability of sports facilities, no matter which type of facility. Yet, given that sports not organized in clubs may be exercised independently of a sports facility-for instance, running - this nonrelation is perhaps not surprising.

Given these results, from now on we concentrate on the impact of the local availability of sports grounds and gyms only. In a next step, we investigate if the above presented shape holds also for specific subpopulations. For this purpose, we repeat the same exercise as above for different strata: we pay particular attention to differences between children in kindergarten (aged 3-6) and school children up to the age of 10 . Moreover, we compare children living on the countryside and children living in bigger cities, children residing in East Germany and children residing in West Germany as well as boys and girls (see Fig. 3).

Figure 3 shows that children 3-6 years old and children $7-$ 10 years old mainly differ in their level of sports participationolder children exercise more-but that there are not many differences in the pattern of how children's sports participation changes with the distance to the next gym/sports ground. In the same vein, although there are notable differences with respect to the level of the physical activity of children living in East and West Germany, the correlation between the physical activity and the local availability of gyms/sports grounds is similar. Also on the gender dimension, boys and girls react rather similarly to the distance to the next gym/sports ground (with the exception that boys seem to increase their sports participation when living between 4 and $6 \mathrm{~km}$ to the next sports facility after having initially decreased their participation at $2 \mathrm{~km}$ ).

The picture changes, however, dramatically when comparing children who live in urban areas with children who live in the countryside. While children living in the countryside exhibit the same pattern as all other subgroups so far, there is no systematic pattern observable for children who live in larger cities. Notice that this result is not only confirmed by a parametric analysis of children's sports participation where we control for individual background characteristics in a probit model (see Table 9 in Appendix 1), but also by the findings of Wicker et al. [20]. There are several possible explanations for this rather erratic picture for children living in a city: (1) the available distance measure might not correspond to the exact walking distancefor instance, there may be shortcuts for pedestrians/cyclists; (2) public transport may allow reaching further location more or less easy; and (3) the density of facilities may be too high in cities to observe any systematic pattern.

Given these caveats for the case of urban areas, our analysis focuses from now on exclusively on children living in less urban areas. Thus, the following estimation results are based on a sample of 3,404 observations living in the "country side", which includes small towns and villages.

\section{Matching results}

Below, we provide estimates for the impact of the local availability of gyms and sports grounds on children's sports engagement in a club. Table 4 displays the three effects of living close to a gym or sports ground on children's sports participation in a club. ${ }^{12}$

In line with the unconditional results, presented in "Unconditional results" section, children who have a gym close by are

\footnotetext{
${ }^{12}$ Results for the impact of living close to a gym/sports ground on children's physical activities outside a club are shown in Table 10 in the Appendix 1.
} 
Fig. 3 Heterogeneity in the relation of the distance to sports facilities to the level of sports participation. Nonparametric kernel regression based on the Epanechnikov kernel. A bandwidth of 0.6 is used for both figures. Distance is measured as straight line. Figure 4 in the appendix provides the same relationships using road distances

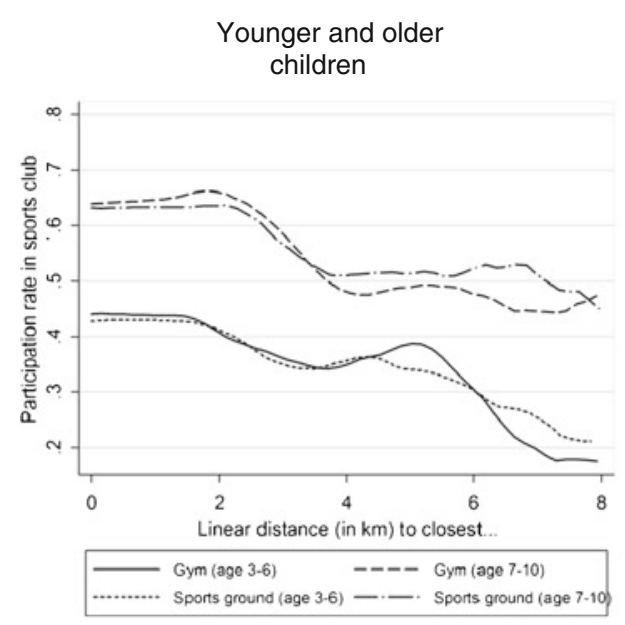

East and West Germany

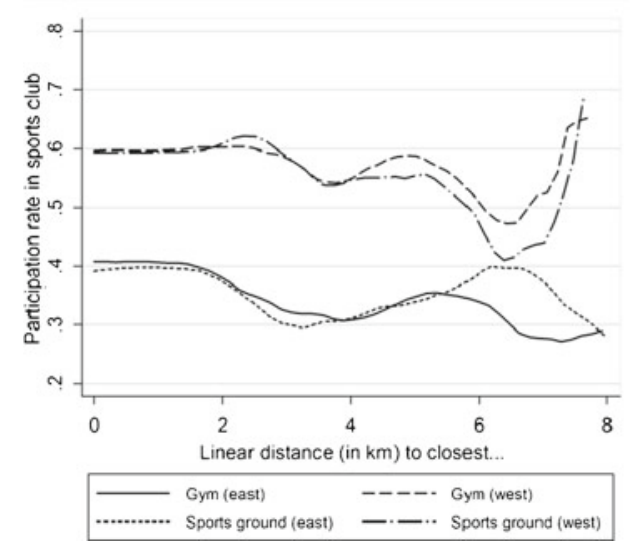

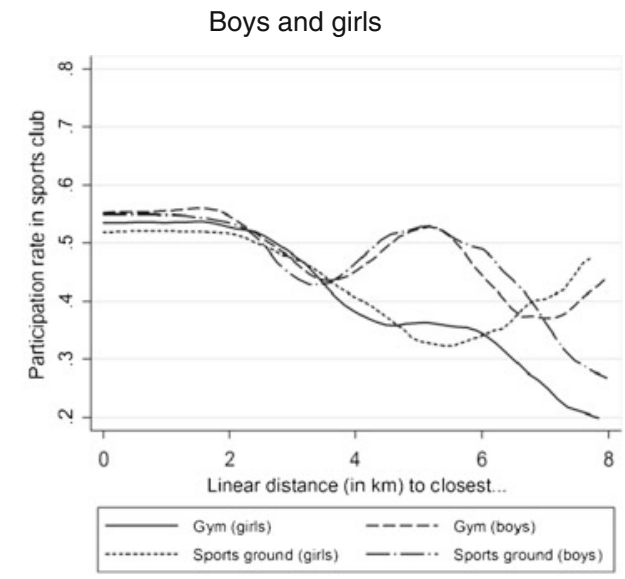

Cities and countryside

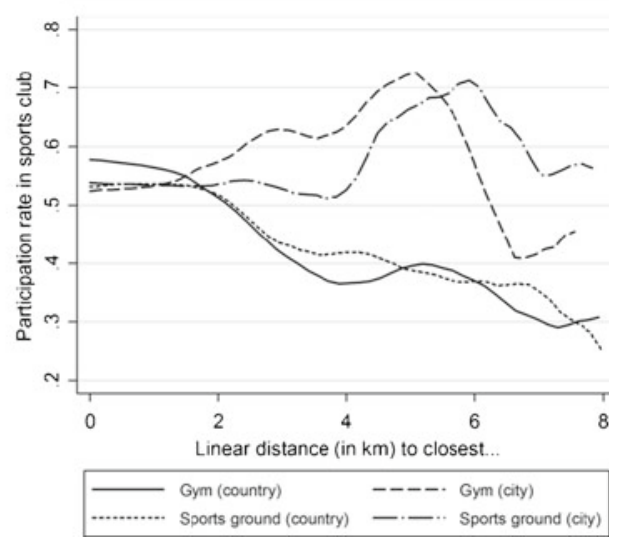

more likely to join a sports club (see Table 4, panel A). The average impact amounts to 13 percentage points (significant at the $1 \%$ level). Given that only $41 \%$ of the control group (see Table 4, column 1) are member of a sports club, this is a nonnegligible effect. Distinguishing between the effect for the children living close and those living further away reveals that this effect is persistent and quite similar across all groups. A child who lives now close to a gym would be 12 percentage points (significant at the $1 \%$ level) less likely to join a sports club if this gym would be removed, while a child who lives now far from a gym would be 14 percentage points (significant at the 5\% level) more likely to join a sports club if a new gym would open up in her vicinity.

The results are similar for the sports ground (see Table 4, panel A), but slightly less pronounced: the overall effect amounts to 9 percentage points, the effect for the treated children to 10 percentage points (both significant at the $5 \%$ level), only the effect for the nontreated children is slightly smaller (and insignificant).

Notice that living close to a sports facility, independently of the type of the sports facility, does not have a significant impact on children's physical activity outside of a sports club (see Table 10, panel A) though — a finding which again coincides with the unconditional results.
Do these average effects differ across different groups of the population? In order to address this question, we again divide our sample into different subgroups-younger children (age 3-6 years old), older children (age 7-10 years old), boys, girls, East and West German children-and estimate the different effects separately for each subgroup. Results are shown in Table 4, panel B, for the treatment "living close to a gym" and in Table 4, panel C, for the treatment "living close to a sports ground". ${ }^{13}$

There are remarkable differences between younger and older children. While for children at school age, the distance to the next gym does not much influence their sports engagement, for children in kindergarten age the distance to the next gym matters. The average treatment effect corresponds to 16 percentage points, and the average treatment effect for the treated amounts to even 22 percentage points (both significant at the $1 \%$ level). The difference between younger and older children might be explained as follows: Firstly, children 36 years old substantially depend on their parents and, thus, living further away from a gym means that parents have to provide considerable transportation services. Secondly, chil-

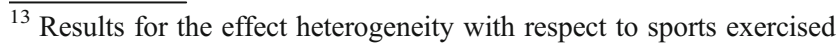
outside a club are shown in panel B and C in Table 10.
} 
Table 4 Effect of living close to a sports facility on participation in a sports club

$\begin{array}{lllllllll}Y_{0}(\mathrm{ATE}) & \text { ATE } & & \text { ATET } & \text { ATENT } & \begin{array}{l}\text { No of } \\ \text { observations }\end{array} & \begin{array}{l}\text { Common } \\ \text { support }\end{array} & \begin{array}{l}\text { Share in common } \\ \text { support }\end{array}\end{array}$

Panel A

Living close $(<2.5 \mathrm{~km})$ to a...

\begin{tabular}{|c|c|c|c|c|c|c|c|c|c|}
\hline Gym & 0.41 & 0.13 & 0 & 0.12 & 1 & 0.14 & 2 & 3,404 & 3,137 \\
\hline Sports ground & 0.40 & 0.09 & 2 & 0.10 & 2 & 0.04 & 32 & 3,404 & 3,004 \\
\hline
\end{tabular}

Panel B

Effect heterogeneity (living close to a gym)

\begin{tabular}{|c|c|c|c|c|c|c|c|c|c|c|}
\hline 3-6 years old & 0.25 & 0.16 & 2 & 0.22 & 0 & 0.04 & 41 & 1,688 & 1,473 & 87.3 \\
\hline $7-10$ years old & 0.48 & 0.08 & 3 & 0.08 & 5 & 0.07 & 13 & 1,716 & 911 & 53.1 \\
\hline Boys & 0.45 & 0.03 & 72 & 0.05 & 42 & 0.00 & 100 & 1,725 & 891 & 51.7 \\
\hline Girls & 0.30 & 0.17 & 0 & 0.19 & 0 & 0.16 & 1 & 1,679 & 907 & 54.0 \\
\hline East Germany & 0.30 & 0.06 & 6 & 0.07 & 17 & 0.06 & 17 & 1,362 & 1,020 & 74.9 \\
\hline West Germany & 0.48 & 0.16 & 0 & 0.18 & 0 & 0.12 & 3 & 2,042 & 734 & 35.9 \\
\hline
\end{tabular}

Panel C

Effect heterogeneity (living close to a sports ground)

\begin{tabular}{|c|c|c|c|c|c|c|c|c|c|c|}
\hline $3-6$ years old & 0.24 & 0.16 & 1 & 0.17 & 0 & 0.09 & 10 & 1,688 & 1,470 & 87.1 \\
\hline $7-10$ years old & 0.49 & 0.04 & 45 & 0.05 & 40 & 0.02 & 87 & 1,716 & 603 & 35.1 \\
\hline Boys & 0.47 & 0.05 & 41 & 0.06 & 38 & 0.01 & 93 & 1,725 & 1,499 & 86.9 \\
\hline Girls & 0.33 & 0.14 & 1 & 0.15 & 1 & 0.08 & 5 & 1,679 & 1,450 & 86.4 \\
\hline East Germany & 0.27 & 0.08 & 6 & 0.09 & 5 & 0.01 & 79 & 1,362 & 1,328 & 97.5 \\
\hline West Germany & 0.41 & 0.21 & 0 & 0.22 & 0 & 0.15 & 0 & 2,042 & 1,616 & 79.1 \\
\hline
\end{tabular}

$P$ values obtained from 999 bootstrap replications

dren 7-10 years old may also be able to exercise sports in a gym either at school or close by the school and, thus, it might be that the distance between facility and school is more important for their club membership than the distance between facility and home.

Girls apparently benefit more from having a gym in their neighborhood: the average effect for girls amounts to 17 percentage points (significant at the $1 \%$ level), while the average effect for boys is rather small (3 percentage points) and insignificant. ${ }^{14}$ This differentially strong impact on

\footnotetext{
${ }^{14}$ Notice that we restrict our sample only to observations that fulfill the common support requirement - in other words, estimation is only performed with observations that have comparable counterparts in the other treatment state. Given the sampling procedure of the KiGGS survey-17,641 children from 167 municipalities were interviewedand the fact that several regional variables, such as the population density or the recreation area, are strong predictors of the distance to the next sports facility (see Appendix 1), ensuring common support reduces the sample significantly (see, for instance, the common support for girls and boys shown in Table 4). Thus, our estimates for the subgroups (which use the same specification of the propensity but of course have lower degrees of freedom and thus higher in-sample predictive power), despite being informative, may lack precision. Therefore, we are able to discuss whether one group may experience a stronger treatment effect than the other, but we cannot necessarily judge if they are significantly different from each other.
}

girls and boys remains when looking at the child living close by or further away: girls who have a gym in their vicinity would reduce their physical activity by 19 percentage points if the gym were removed, while girls who live further away from the next gym would increase their physical activity by 16 percentage points if a gym were built in their vicinity.

Lastly, the availability of sports facilities influences children's sports club participation much stronger in West Germany than in East Germany: while West German children are on average 16 percentage points more likely to join a club when there is a gym close by, East German children increase their club activity by only 6 percentage points when they live close to a gym. $^{15}$ The strong difference between East and West German children remains when comparing the effects for the treated and nontreated children ( 7 versus 18 percentage points and 6 versus 12 percentage points, respectively). One explanation may be that in the former German Democratic Republic there was no real culture to perform

\footnotetext{
${ }^{15}$ Given the strong predictive power of the population density, the common support condition is fulfilled only for $36 \%$ of the West German children.
} 
sports in sports clubs and, thus, the existence of a gym in the neighborhood may not encourage East German children to join a sports club. As a consequence, increased effort to open up more gyms in East Germany does not seem to lead to a closure of the notable difference in the sports engagement between East and West German children (30\% versus $48 \%)$.

The results shown in Table 4, panel C, allow us to analyze as well if there is any heterogeneity in the effect of living close to a sports ground across the different subgroups. The picture is similar to the picture just provided for living close to a gym. Younger children react much more to the availability of a sports ground than older children, so do girls as well as children in West Germany. Explanations for these findings are probably similar to the ones provided above for the gyms. Yet, in the end, they remain speculations.

\section{Conclusions}

In this paper, we analyze the impact of the distance between children's home and various sports facilities on the sports activity of children who are 3-10 years old. We base this analysis on informative individual data from the KiGGS, a comprehensive, Germany-wide dataset. Our main empirical results stem from robust econometric methods based on optimized propensity score matching estimators. They suggest that differences in distances to facilities do not matter much in larger cities, which is probably not surprising given the high density of facilities in such locations. However, in smaller cities and villages, they matter substantially. Moving closer to a facility may easily increase a child's likelihood to participate in some sports (organized by a sports club) by more than 10 percentage points.

These results are interesting in light of the findings of previous research. Wicker et al. [20], for instance, found a positive link between the overall population's physical activity and the supply of sports facilities within a major city. At first sight, this finding may contradict the absence of any impact of the local supply of sports facilities on the sports participation of children living in a city in our study. Notice, however, that when restricting their sample to children age 3-18, Wicker et al. [20] also do not detect any link between children's sports activities and the local supply of sports facilities, with the exception of swimming pools.

Investigating a potential heterogeneous effect of the supply of sports facilities for children of different ages is interesting per se. It seems that the availability of sports facilities, such as gyms and sports grounds, matters more for kindergarten children who are not yet fully integrated in the educational system, and thus are not yet exposed to the different aspects of daily school life, such as meeting classmates, following disciplinary rules, etc. From a policy perspective, our findings are thus relevant as it seems that by offering more sports facilities one can promote the integration of children into the society already during the early life stage.

Besides the differential impact of the supply of sports facilities on children from different age groups, we also find interesting heterogeneity along other dimensions. The effects are considerably larger for girls than for boys, and for children living in West Germany than for children in East Germany. However, these effects may be valid only for sports exercised in sports clubs and not for sports done outside of clubs.

Taken together, given that one may safely conjecture that sports activities improve the health of the children, increasing the number of facilities in the vicinity of children's residence is an investment that improves public health (although, of course, our results are silent about its cost-effectiveness).

Our study can be improved in many dimensions, though. For example, currently the KiGGS has a crosssectional design and thus, we are not able to exploit or take care of any dynamics. A panel dataset could not only help to improve the identification of the estimated effects but could also help to uncover some interesting dynamics in physical activities of children when children age. Obviously, one desires a more precise and detailed measurement of the type of activities jointly with a larger sample that allows investigating the heterogeneity in a more robust way. Finally, one may want to use the distance measures indirectly to obtain a more convincing identification of the effect of sports activity on children's health and educational progress, for example by using an instrumental variable strategy. Indeed, this is the idea of the paper by Felfe et al. [24].

Acknowledgments This project received financial support from the St. Gallen Research Center for Ageing, Welfare, and Labour Market Analysis (SCALA). We are very much indebted to the Robert-Koch Institut in Berlin, in particular Dr. Martin Schlaud and Dr. Heribert Stolzenberg for providing the data of the KiGGS study, helping us to better understand it, and to organize a process that allowed us to merge the sports facility information to the individual data. A previous version of the paper was presented at the 2nd European Conference on Sports Economics (ECSE) in Cologne 2010. We thank participants for helpful comments. Furthermore, two anonymous referees helped us to considerable improve a previous version of the paper. The usual disclaimer applies. 


\section{Appendix 1}

Further descriptive statistics and results

Table 5 Descriptive statistics of the control variables

\begin{tabular}{|c|c|c|c|c|c|c|c|}
\hline & & \multicolumn{2}{|l|}{ Total } & \multicolumn{2}{|c|}{ Distance to $\mathrm{gym} \leq 2.5 \mathrm{~km}$} & \multicolumn{2}{|c|}{ Distance to gym $>2.5 \mathrm{~km}$} \\
\hline & & Mean & $\mathrm{SD}$ & Mean & SD & Mean & SD \\
\hline \multicolumn{8}{|l|}{ Children's characteristics } \\
\hline \multicolumn{2}{|l|}{ Age (in years) } & 6.57 & 2.27 & 6.58 & 2.27 & 6.52 & 2.31 \\
\hline \multicolumn{2}{|l|}{ Gender $(1=$ male, $0=$ female $)$} & 0.51 & & 0.51 & & 0.50 & \\
\hline \multicolumn{2}{|l|}{ German background } & 0.87 & & 0.85 & & 0.97 & \\
\hline \multicolumn{8}{|l|}{ Parents' characteristics } \\
\hline \multicolumn{2}{|l|}{ Single parent household } & 0.10 & & 0.11 & & 0.07 & \\
\hline \multirow[t]{5}{*}{ Mother's education } & Basic & 0.20 & & 0.21 & & 0.16 & \\
\hline & Intermediate & 0.45 & & 0.42 & & 0.57 & \\
\hline & High school & 0.15 & & 0.16 & & 0.12 & \\
\hline & University & 0.16 & & 0.16 & & 0.13 & \\
\hline & Other & 0.04 & & 0.04 & & 0.02 & \\
\hline \multirow[t]{5}{*}{ Father's education } & Basic & 0.25 & & 0.25 & & 0.24 & \\
\hline & Intermediate & 0.34 & & 0.31 & & 0.47 & \\
\hline & High school & 0.10 & & 0.11 & & 0.07 & \\
\hline & University & 0.22 & & 0.23 & & 0.15 & \\
\hline & Other & 0.04 & & 0.04 & & 0.02 & \\
\hline \multirow[t]{4}{*}{ Mother's BMI } & Underweight & 0.03 & & 0.03 & & 0.02 & \\
\hline & Normal & 0.63 & & 0.63 & & 0.62 & \\
\hline & Overweight & 0.22 & & 0.22 & & 0.24 & \\
\hline & Obese & 0.11 & & 0.11 & & 0.11 & \\
\hline \multirow[t]{3}{*}{ Social class } & Low & 0.27 & & 0.27 & & 0.27 & \\
\hline & Medium & 0.46 & & 0.45 & & 0.52 & \\
\hline & High & 0.26 & & 0.28 & & 0.20 & \\
\hline \multirow[t]{3}{*}{ Smoking during pregnancy } & Regularly & 0.05 & & 0.05 & & 0.03 & \\
\hline & Occasionally & 0.12 & & 0.13 & & 0.09 & \\
\hline & Never & 0.82 & & 0.81 & & 0.86 & \\
\hline \multicolumn{8}{|l|}{ Neighborhood characteristics } \\
\hline \multicolumn{2}{|l|}{ East Germany } & 0.33 & & 0.28 & & 0.59 & \\
\hline \multirow[t]{4}{*}{ Municipality size } & Village & 0.36 & & 0.28 & & 0.79 & \\
\hline & Small town & 0.12 & & 0.14 & & 0.04 & \\
\hline & Medium town & 0.31 & & 0.34 & & 0.14 & \\
\hline & City & 0.21 & & 0.24 & & 0.03 & \\
\hline \multicolumn{2}{|c|}{ Population density (inhabitants $/ \mathrm{km}^{2}$ ) } & 733.19 & 887.10 & 838.24 & 918.80 & 184.75 & 360.40 \\
\hline \multicolumn{2}{|l|}{ Recreation area/capita $\left(\mathrm{m}^{2}\right)$} & 39.99 & 37.44 & 36.50 & 30.51 & 58.23 & 58.86 \\
\hline \multicolumn{2}{|l|}{ Tax income/capita (Euro) } & 551.80 & 251.63 & 579.59 & 252.10 & 406.76 & 192.49 \\
\hline \multicolumn{2}{|l|}{ Share of population $<18$ years } & 16.92 & 3.14 & 17.12 & 3.12 & 15.89 & 3.06 \\
\hline
\end{tabular}

Note: Table includes only variables that are used in one of the estimation steps 
Table 6 Selection of estimation sample

\begin{tabular}{lcl}
\hline Sample & No. of observations & Comment \\
\hline Full sample & 17,641 & Full KiGGS dataset including children aged 0-17 years \\
Age group 3-10 years & 8,023 & $\begin{array}{c}\text { Only observations of children aged 3-10 years are used as information on } \\
\text { sports participation in- and outside clubs is only available for them }\end{array}$ \\
Distance to facilities available & 7,473 & $\begin{array}{l}\text { Number of observations where the distance could be estimated } \\
\text { Sports participation available }\end{array}$ \\
Final sample & 6,998 & $\begin{array}{l}\text { Number of observations with nonmissing answers on the questions regarding } \\
\text { sports participation }\end{array}$ \\
\end{tabular}

Table 7 Results of propensity score estimation for distance to next gym and distance to nearest sports ground: country sample

\begin{tabular}{|c|c|c|c|c|c|}
\hline & & \multicolumn{2}{|l|}{ Gym } & \multicolumn{2}{|c|}{ Sports ground } \\
\hline & & Coefficient & $p$ value $\%$ & Coefficient & $p$ value $\%$ \\
\hline Constant & & -0.75 & 19.5 & -1.69 & 0.7 \\
\hline Gender $(1=$ male, $0=$ female $)$ & & 0.05 & 36.1 & -0.03 & 65.8 \\
\hline \multirow[t]{8}{*}{ Age in years } & 3 & -0.02 & 81.5 & -0.23 & 5.4 \\
\hline & 4 & 0.02 & 87.3 & -0.11 & 36.8 \\
\hline & 5 & 0.06 & 54.9 & -0.09 & 44.5 \\
\hline & 6 (reference) & & & & \\
\hline & 7 & -0.04 & 67.7 & -0.14 & 25.3 \\
\hline & 8 & 0.03 & 76.6 & -0.07 & 55.7 \\
\hline & 9 & -0.06 & 59.8 & -0.19 & 11.3 \\
\hline & 10 & -0.03 & 75.3 & -0.22 & 7.3 \\
\hline German background & & -0.48 & 0.1 & -0.66 & 0.1 \\
\hline \multirow[t]{4}{*}{ Mother's education } & Basic & 0.00 & 98.4 & 0.07 & 45.1 \\
\hline & Intermediate (reference) & & & & \\
\hline & High school & -0.16 & 7.7 & 0.08 & 42.8 \\
\hline & University & 0.05 & 61.5 & -0.10 & 37.3 \\
\hline \multirow[t]{4}{*}{ Father's education } & Basic & -0.16 & 3.5 & -0.20 & 1.7 \\
\hline & Intermediate (reference) & & & & \\
\hline & High school & 0.04 & 69.4 & -0.15 & 19.4 \\
\hline & University & 0.11 & 34.3 & -0.19 & 12.0 \\
\hline \multirow[t]{3}{*}{ Mother's BMI } & Underweight or Normal (reference) & & & & \\
\hline & Overweight & 0.02 & 74.0 & 0.07 & 34.9 \\
\hline & Obese & 0.00 & 98.2 & 0.01 & 95.5 \\
\hline \multirow[t]{3}{*}{ East Germany $\times$ social class } & Low & -0.12 & 20.4 & -0.21 & 4.3 \\
\hline & Medium (reference) & & & & \\
\hline & High & -0.08 & 52.1 & -0.01 & 92.6 \\
\hline \multirow[t]{3}{*}{ West Germany × social class } & Low & -0.10 & 33.2 & -0.15 & 18.0 \\
\hline & Medium (reference) & & & & \\
\hline & High & 0.04 & 75.3 & 0.20 & 17.7 \\
\hline Single parent household & & 0.29 & 0.5 & 0.22 & 6.0 \\
\hline Smoking during pregnancy: never & & -0.06 & 43.5 & 0.02 & 84.8 \\
\hline East Germany & & -0.40 & 53.5 & 2.10 & 0.4 \\
\hline \multirow[t]{2}{*}{ Municipality size } & Village & -0.78 & 0.0 & -0.26 & 4.2 \\
\hline & Small towns (reference) & & & & \\
\hline \multirow[t]{2}{*}{ East Germany $\times$ population density } & $(=$ Low $)$ & -0.33 & 1.5 & -0.25 & 11.8 \\
\hline & (=Medium or High) (reference) & & & & \\
\hline
\end{tabular}


Table 7 (continued)

\begin{tabular}{|c|c|c|c|c|c|}
\hline & & \multicolumn{2}{|l|}{ Gym } & \multicolumn{2}{|c|}{ Sports ground } \\
\hline & & Coefficient & $p$ value $\%$ & Coefficient & $p$ value $\%$ \\
\hline \multirow[t]{2}{*}{ West Germany $\times($ population density $=$ low $)$} & & 0.12 & 30.7 & 0.24 & 8.0 \\
\hline & (=Medium or high) (reference) & & & & \\
\hline \multirow[t]{3}{*}{ East Germany $\times$ recreation area } & (=Low) & -0.71 & 0.0 & 0.38 & 0.5 \\
\hline & (=Medium) (reference) & & & & \\
\hline & (=High) & -0.10 & 44.0 & 0.35 & 0.3 \\
\hline \multirow[t]{3}{*}{ West Germany $\times$ recreation area } & (=Low) & 0.51 & 0.0 & 0.23 & 4.6 \\
\hline & (=Medium) (reference) & & & & \\
\hline & (=High) & 0.32 & 0.1 & 0.04 & 69.5 \\
\hline \multirow[t]{3}{*}{ East Germany $\times$ tax income } & (=Low) & 0.76 & 0.0 & 0.76 & 0.0 \\
\hline & (=Medium) (reference) & & & & \\
\hline & (=High) & -0.64 & 0.0 & 0.04 & 75.8 \\
\hline \multirow[t]{3}{*}{ West Germany $\times$ tax income } & (=Low) & -0.26 & 0.4 & -0.01 & 88.7 \\
\hline & (=Medium) (reference) & & & & \\
\hline & (=High) & -0.18 & 12.2 & -0.35 & 0.5 \\
\hline \multirow[t]{3}{*}{ East Germany× population share below 18 years } & (=Low) & 0.38 & 0.0 & 0.02 & 82.4 \\
\hline & (=Medium) (reference) & & & & \\
\hline & (=High) & -0.04 & 68.5 & -0.18 & 9.6 \\
\hline \multirow[t]{3}{*}{ West Germany $\times$ population share below 18 years } & $(=$ Low $)$ & -0.25 & 2.9 & 0.22 & 9.0 \\
\hline & (=Medium) (reference) & & & & \\
\hline & (=High) & 0.43 & 0.0 & 0.31 & 0.1 \\
\hline \multicolumn{2}{|l|}{ East Germany $\times \log$ (population density) } & 0.58 & 0.0 & 0.26 & 0.6 \\
\hline \multicolumn{2}{|l|}{ West Germany $\times \log$ (population density) } & 0.57 & 0.0 & 0.78 & 0.0 \\
\hline
\end{tabular}

Note: Coefficients from a probit model. Dependent variable is an indicator for distance less than $2.5 \mathrm{~km}$. Efron's Pseudo $R^{2}$ is 0.32 for gyms and 0.13 for sports grounds

Table 8 The dependence of sports participation rate on the distances conditional on covariates: country sample

\begin{tabular}{|c|c|c|c|c|c|c|c|}
\hline & \multirow[t]{2}{*}{ No. of observations } & \multicolumn{3}{|l|}{ Sports in club } & \multicolumn{3}{|c|}{ Sports not in club } \\
\hline & & Unconditional & Conditional & SD & Unconditional & Conditional & SD \\
\hline \multicolumn{8}{|l|}{ Gym } \\
\hline $0-0.5 \mathrm{~km}$ & 1,005 & 0.59 & 0.56 & 0.02 & 0.51 & 0.53 & 0.02 \\
\hline $0.5-1 \mathrm{~km}$ & 802 & 0.55 & 0.52 & 0.02 & 0.50 & 0.50 & 0.02 \\
\hline $1-1.5 \mathrm{~km}$ & 340 & 0.53 & 0.50 & 0.03 & 0.53 & 0.52 & 0.03 \\
\hline $1.5-2 \mathrm{~km}$ & 197 & 0.50 & 0.49 & 0.04 & 0.52 & 0.52 & 0.04 \\
\hline $2-2.5 \mathrm{~km}$ & 129 & 0.54 & 0.53 & 0.04 & 0.59 & 0.58 & 0.04 \\
\hline $2.5-3 \mathrm{~km}$ & 132 & 0.42 & 0.43 & 0.04 & 0.52 & 0.52 & 0.04 \\
\hline $3-4 \mathrm{~km}$ & 267 & 0.32 & 0.38 & 0.03 & 0.54 & 0.55 & 0.03 \\
\hline $4-5 \mathrm{~km}$ & 220 & 0.39 & 0.45 & 0.03 & 0.46 & 0.46 & 0.04 \\
\hline $5+\mathrm{km}$ & 312 & 0.36 & 0.47 & 0.03 & 0.48 & 0.46 & 0.03 \\
\hline \multicolumn{8}{|c|}{ Sports ground } \\
\hline $0-0.5 \mathrm{~km}$ & 957 & 0.52 & 0.52 & 0.02 & 0.52 & 0.52 & 0.02 \\
\hline $0.5-1 \mathrm{~km}$ & 960 & 0.52 & 0.50 & 0.02 & 0.50 & 0.50 & 0.02 \\
\hline $1-1.5 \mathrm{~km}$ & 533 & 0.57 & 0.53 & 0.02 & 0.50 & 0.49 & 0.02 \\
\hline $1.5-2 \mathrm{~km}$ & 284 & 0.49 & 0.52 & 0.03 & 0.51 & 0.51 & 0.03 \\
\hline $2-2.5 \mathrm{~km}$ & 178 & 0.47 & 0.52 & 0.04 & 0.53 & 0.55 & 0.04 \\
\hline $2.5-3 \mathrm{~km}$ & 77 & 0.35 & 0.35 & 0.05 & 0.56 & 0.53 & 0.06 \\
\hline $3-4 \mathrm{~km}$ & 180 & 0.42 & 0.44 & 0.04 & 0.53 & 0.51 & 0.04 \\
\hline
\end{tabular}


Table 8 (continued)

\begin{tabular}{|c|c|c|c|c|c|c|c|}
\hline & \multirow[t]{2}{*}{ No. of observations } & \multicolumn{3}{|l|}{ Sports in club } & \multicolumn{3}{|c|}{ Sports not in club } \\
\hline & & Unconditional & Conditional & SD & Unconditional & Conditional & $\mathrm{SD}$ \\
\hline $4-5 \mathrm{~km}$ & 105 & 0.42 & 0.48 & 0.04 & 0.50 & 0.50 & 0.05 \\
\hline $5+\mathrm{km}$ & 130 & 0.34 & 0.46 & 0.04 & 0.48 & 0.49 & 0.05 \\
\hline
\end{tabular}

Results from probit estimations with the respective sports activities as dependent variables. Dummies for distances (shown) and the control variables of the propensity score are included as explanatory variables. Average discrete effects of the distance dummies and their standard error are shown. Standard errors obtained from 999 bootstrap replications. Efron's Pseudo $R^{2}$ is 0.14 for sports in clubs using distance to gym and 0.14 for distance to sports ground. For sports outside clubs and distance to gym as well as distance to sports ground Efron's Pseudo $R^{2}$ is 0.03

Table 9 The dependence of sports participation on the distances conditional on covariates: city sample

\begin{tabular}{|c|c|c|c|c|c|c|c|}
\hline & \multirow[t]{2}{*}{ No. of observations } & \multicolumn{3}{|l|}{ Sports in club } & \multicolumn{3}{|c|}{ Sports not in club } \\
\hline & & Unconditional & Conditional & SD & Unconditional & Conditional & SD \\
\hline \multicolumn{8}{|l|}{ Gym } \\
\hline $0-0.5 \mathrm{~km}$ & 1,911 & 0.50 & 0.53 & 0.01 & 0.49 & 0.50 & 0.01 \\
\hline $0.5-1 \mathrm{~km}$ & 1,028 & 0.55 & 0.53 & 0.01 & 0.50 & 0.49 & 0.02 \\
\hline $1-1.5 \mathrm{~km}$ & 264 & 0.50 & 0.47 & 0.03 & 0.45 & 0.44 & 0.03 \\
\hline $1.5-2 \mathrm{~km}$ & 112 & 0.57 & 0.52 & 0.04 & 0.57 & 0.57 & 0.05 \\
\hline $2-2.5 \mathrm{~km}$ & 85 & 0.68 & 0.60 & 0.05 & 0.48 & 0.47 & 0.06 \\
\hline $2.5-3 \mathrm{~km}$ & 51 & 0.65 & 0.60 & 0.06 & 0.57 & 0.56 & 0.07 \\
\hline $3-4 \mathrm{~km}$ & 80 & 0.58 & 0.56 & 0.05 & 0.46 & 0.47 & 0.05 \\
\hline $4-5 \mathrm{~km}$ & 36 & 0.75 & 0.69 & 0.07 & 0.50 & 0.51 & 0.08 \\
\hline $5+\mathrm{km}$ & 27 & 0.52 & 0.47 & 0.09 & 0.59 & 0.58 & 0.10 \\
\hline \multicolumn{8}{|c|}{ Sports ground } \\
\hline $0-0.5 \mathrm{~km}$ & 1,084 & 0.54 & 0.54 & 0.01 & 0.49 & 0.50 & 0.02 \\
\hline $0.5-1 \mathrm{~km}$ & 1,405 & 0.52 & 0.52 & 0.01 & 0.48 & 0.48 & 0.01 \\
\hline $1-1.5 \mathrm{~km}$ & 687 & 0.53 & 0.53 & 0.02 & 0.51 & 0.50 & 0.02 \\
\hline $1.5-2 \mathrm{~km}$ & 229 & 0.55 & 0.57 & 0.03 & 0.50 & 0.50 & 0.03 \\
\hline $2-2.5 \mathrm{~km}$ & 71 & 0.54 & 0.49 & 0.05 & 0.51 & 0.51 & 0.06 \\
\hline $2.5-3 \mathrm{~km}$ & 40 & 0.58 & 0.53 & 0.07 & 0.55 & 0.55 & 0.08 \\
\hline $3-4 \mathrm{~km}$ & 36 & 0.39 & 0.37 & 0.07 & 0.53 & 0.52 & 0.08 \\
\hline $4-5 \mathrm{~km}$ & 20 & 0.65 & 0.58 & 0.10 & 0.60 & 0.59 & 0.12 \\
\hline $5+\mathrm{km}$ & 22 & 0.64 & 0.60 & 0.11 & 0.50 & 0.51 & 0.11 \\
\hline
\end{tabular}

See note below Table 8. Efron's Pseudo $R^{2}$ is 0.16 for sports in clubs using distance to gym and 0.16 for distance to sports ground. For sports outside clubs and distance to gym Efron's Pseudo $R^{2}$ is 0.03 and for distance to sports ground 0.02

Table 10 Effect of living close to a sports facility on participation in sports outside a club

\begin{tabular}{|c|c|c|c|c|c|c|c|c|c|}
\hline \multirow[t]{2}{*}{$Y_{0}(\mathrm{ATE})$} & \multicolumn{2}{|c|}{ ATE } & \multicolumn{2}{|l|}{ ATET } & \multicolumn{2}{|c|}{ ATENT } & \multirow{2}{*}{$\begin{array}{l}\text { No. of } \\
\text { observations }\end{array}$} & \multirow{2}{*}{$\begin{array}{l}\text { Common } \\
\text { Support }\end{array}$} & \multirow{2}{*}{$\begin{array}{l}\text { Share in common } \\
\text { support }\end{array}$} \\
\hline & $\theta$ & $p$ value $\%$ & $\theta$ & $p$ value $\%$ & $\Theta$ & $p$ value $\%$ & & & \\
\hline
\end{tabular}

Panel A

Living close $(<2.5 \mathrm{~km})$ to...

\begin{tabular}{|c|c|c|c|c|c|c|c|c|c|c|}
\hline Gym & 0.46 & 0.08 & 18 & 0.08 & 27 & 0.06 & 16 & 3,404 & 3,137 & 92.2 \\
\hline Sports ground & 0.52 & 0.01 & 78 & 0.00 & 99 & 0.06 & 24 & 3,404 & 3,004 & 88.2 \\
\hline
\end{tabular}

Panel B

Effect heterogeneity (living close to gym)
3-6 Years old
0.41
0.11
16
$0.11 \quad 33$
$0.11 \quad 4$
1,688
1,473 
Table 10 (continued)

\begin{tabular}{|c|c|c|c|c|c|c|c|c|c|c|}
\hline & \multirow{2}{*}{$Y_{0}(\mathrm{ATE})$} & \multicolumn{2}{|l|}{ ATE } & \multicolumn{2}{|l|}{ ATET } & \multicolumn{2}{|c|}{ ATENT } & \multirow{2}{*}{$\begin{array}{l}\text { No. of } \\
\text { observations }\end{array}$} & \multirow{2}{*}{$\begin{array}{l}\text { Common } \\
\text { Support }\end{array}$} & \multirow{2}{*}{$\begin{array}{l}\text { Share in common } \\
\text { support }\end{array}$} \\
\hline & & $\theta$ & $p$ value $\%$ & $\theta$ & $p$ value $\%$ & $\Theta$ & $p$ value $\%$ & & & \\
\hline $7-10$ Years old & 0.56 & -0.01 & 77 & -0.04 & 39 & 0.02 & 65 & 1,716 & 911 & 53.1 \\
\hline Boys & 0.56 & 0.03 & 50 & -0.04 & 58 & 0.11 & 12 & 1,725 & 891 & 51.7 \\
\hline Girls & 0.54 & -0.04 & 41 & -0.10 & 23 & 0.03 & 55 & 1,679 & 907 & 54.0 \\
\hline East Germany & 0.50 & 0.04 & 35 & 0.00 & 94 & 0.08 & 8 & 1,362 & 1,020 & 74.9 \\
\hline West Germany & 0.62 & -0.10 & 25 & -0.12 & 36 & -0.05 & 35 & 2,042 & 734 & 35.9 \\
\hline \multicolumn{11}{|l|}{ Panel C } \\
\hline \multicolumn{11}{|c|}{ Effect heterogeneity (living close to sports ground) } \\
\hline 3-6 Years old & 0.41 & 0.08 & 10 & 0.09 & 10 & 0.03 & 60 & 1,688 & 1,470 & 87.1 \\
\hline 7-10 Years old & 0.52 & 0.02 & 79 & 0.01 & 91 & 0.05 & 60 & 1,716 & 603 & 35.1 \\
\hline Boys & 0.57 & -0.02 & 63 & -0.03 & 55 & 0.02 & 69 & 1,725 & 1,499 & 86.9 \\
\hline Girls & 0.51 & 0.00 & 93 & -0.01 & 84 & 0.05 & 32 & 1,679 & 1,450 & 86.4 \\
\hline East Germany & 0.43 & 0.09 & 4 & 0.11 & 4 & 0.05 & 34 & 1,362 & 1,328 & 97.5 \\
\hline West Germany & 0.58 & -0.06 & 20 & -0.06 & 28 & -0.09 & 8 & 2,042 & 1,616 & 79.1 \\
\hline
\end{tabular}

$P$ values obtained from 999 bootstrap replications

Fig. 4 Nonparametric estimates of the relation of the distance by road to different sports facilities and sports participation. No further covariates included. Nonparametric kernel regression based on the Epanechnikov kernel with a bandwidth of 0.6 (both figures)
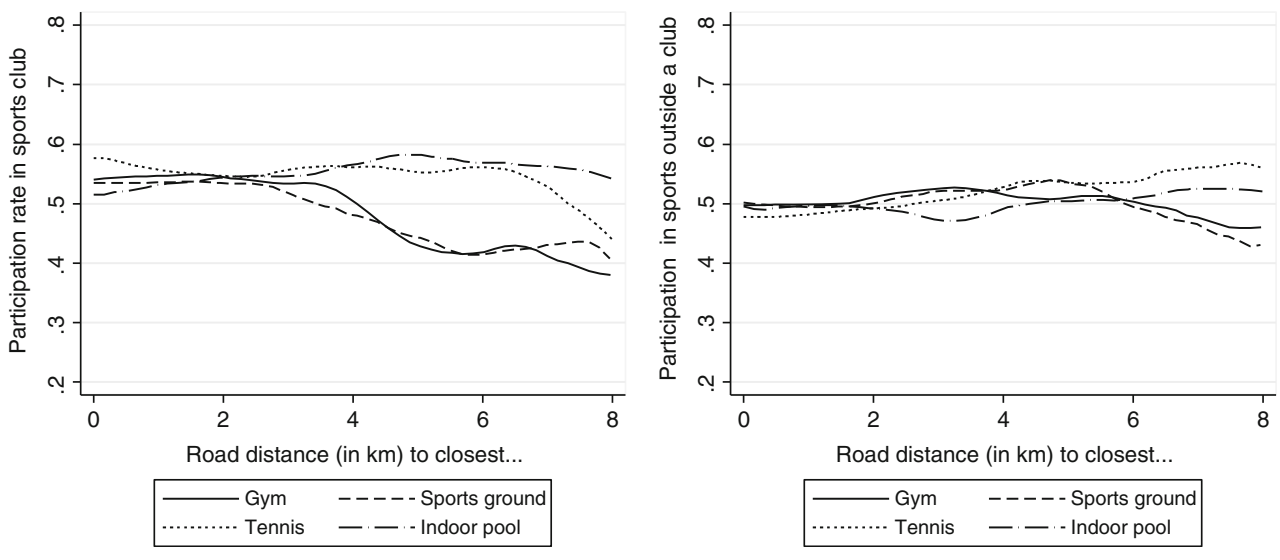

\section{Appendix 2}

Further details on the matching estimator used

Table 11 A matching protocol for the estimation of a counterfactual outcome and the effects (ATET)

Step A-1

Step B-1

Step C-1

Step D-1

Step A-2

Step B-2
Choose one observation in the subsample defined by $d=1$ and delete it from that pool

Find an observation in the subsample defined by $d=0$ that is as close as possible to the one chosen in step A-1 in terms of $p(x), \widetilde{x}$. 'Closeness' is based on the Mahalanobis distance

Repeat A-1 and B-1 until no observation with $d=1$ is left

Compute the maximum distance (dist) obtained for any comparison between a member of the reference distribution and matched comparison observations

Repeat A-1

Repeat B-1. If possible, find other observations in the subsample of $d=0$ that are at least as close as $R \times$ dist to the one chosen in step A-2. Do not remove these observations, so that they can be used again. Compute weights for all chosen comparisons observations that are proportional to their distance. Normalize the weights such that they add to one 
Step C-2

Step D-2

Step E

Step F-1

Step F-2

Step G
Repeat A-2 and B-2 until no participant in $d=1$ is left

D-2, For any potential comparison observation, add the weights obtained in A-2 and B-2

Using the weights $w\left(x_{i}\right)$ obtained in $\mathrm{D}-2$, run a weighted linear regression of the outcome variable on the variables used to define the distance (and an intercept)

Predict the potential outcome $y^{0}\left(x_{i}\right)$ of every observation using the coefficients of this regression: $\hat{y}^{0}\left(x_{i}\right)$

Estimate the bias of the matching estimator for $E\left(Y^{0} \mid D=1\right)$ as: $\sum_{i=1}^{N} \frac{d_{i} \hat{y}^{0}\left(x_{i}\right)}{N_{1}}-\frac{\left(1-d_{i}\right) w_{i} \hat{y}^{0}\left(x_{i}\right)}{N_{0}}$

Using the weights obtained by weighted matching in D-2, compute a weighted mean of the outcome variables in $d=0$. Subtract the bias from this estimate to get $E\left(Y^{0} \mid D=1\right)$

$R$ is set to 90 percentage points

This appendix describes the baseline protocol used for the matching estimator.

The parameter used to define the radius for the distanceweighted radius matching $(R)$ is set to 90 percentage points. This value refers to the distance of the worst match in a one-to-one matching and is defined in terms of the propensity score. Furthermore, whenever a single weight has a share larger than $6 \%$ compared to the overall sum of weights, the corresponding observation was removed (see [25] for details).

When estimating the effect for the nontreated the same protocol is used but the role of treated and nontreated is reversed. Finally, the ATE is the weighted sum of the ATET and the ATENT where the weights are the share of the treated and the share of the nontreated, respectively.

\section{References}

1. Lakdawalla D, Philipson T (2007) Labor supply and weight. J Hum Resour 42(1):85-116

2. Lechner M (2009) Long-run labour market effects of individual sports activities. J Heal Econ 28(4):839-854

3. Gomez-Pinilla F (2008) The influences of diet and exercise on mental health through hormensis. Aging Res Rev 7(1):49-62

4. Rashad I (2007) Cycling: an increasingly untouched source of physical and mental health. NBER Working Paper 12929

5. Europäische Kommission (2010) Sport und körperliche Betätigung. 2010. Spezial-Eurobarometer 72.3. http://ec.europa.eu/public_opinion/ archives/ebs/ebs_334_de.pdf. Accessed 10 May 2011

6. Kutteroff A, Behrens P (2006) KIM Studie 2006: Kinder und Medien, Computer und Internet. Medienpädagogischer Forschungsverbund Südwest. http://www.mpfs.de/fileadmin/KIMpdf06/KIM2006.pdf. Accessed 10 May 2011

7. Telama R et al (2005) Physical activity from childhood to adulthood: a 21-year tracking study. Am J Prev Med 28(3):267-273

8. Case A, Fertig A, Paxson C (2005) The lasting impact of childhood health and circumstance. J Heal Econ 24(2):365-389

9. Gratton C, Taylor P (2000) The economics of sport and recreation. Taylor and Francis, London
10. Ahlert G (2004) Investive Sportförderung in der Bundesrepublik. GWS Discussion Paper 04-2

11. Limstrand $\mathrm{T}$ (2008) Environmental characteristics relevant to young people's use of sports facilities: a review. Scand J Med Sci 18(3):275-287

12. Seefeldt V, Malina R, Clark M (2002) Factors affecting levels of physical activity in adults. Sports Med 32(3):143-168

13. Sallis J, Prochaska J, Taylor W (2000) A review of correlates of phyiscal activity of children and adolescents. Med Sci Sports Exerc 32(5):963-975

14. Boone-Heinonen J et al (2010) Where can they play? Outdoor spaces and physical activity among adolescents in U.S. urbanized areas. Prev Med 51(3-4):295-298

15. Susan B et al (2008) Physical activity among adolescents: when do parks matter? Am J Prev Med 34(4):345-348

16. Humphreys B, Ruseski J (2007) Participation in physical activity and government spending on parks and recreation. Contemp Econ Policy 25(4):538-552

17. Kaczynski A, Potwarka L, Saelens B (2008) Association of park size, distance, and features with physical activity in neighborhood parks. Am J Public Health 98(8):1451-1456

18. Huston S et al (2003) Neighborhood environment, access to places for activity, and leisure-time physical activity in a diverse North Carolina population. Am J Heal Promot 18 (1):58-69

19. Pawlowski $\mathrm{T}$ et al (2009) Travel time spending behaviour in recreational sports: an econometric approach with management implications. Eur Sport Manag Q 9(3):215-242

20. Wicker P, Breuer C, Pawlowski T (2009) Promoting sport for all to age-specific target groups: the impact of sport infrastructure. Eur Sport Manag Q 9(2):103-118

21. Deutsche Olympische Gesellschaft (1961) Der Goldene Plan in den Gemeinden. Ein Handbuch. Limpert, Frankfurt am Main

22. Hübner H (2003) Sportstättenentwicklungsplanung in Deutschland. Notizen zur gegenwärtigen Situation. dvs-Informationen 18 (2):21-25

23. Kurth B et al (2008) The challenge of comprehensively mapping children's health in a nation-wide health survey: design of the German KiGGS study. BMC Publ Health 8:196-204

24. Felfe C, Lechner M, Steinmayr A (2011) Sports and child development. CEPR Discussion Papers 8523.

25. Huber M, Lechner M, Wunsch C (2010) How to control for many covariates? Reliable estimators based on the propensity score. IZA discussion paper no. 5268 